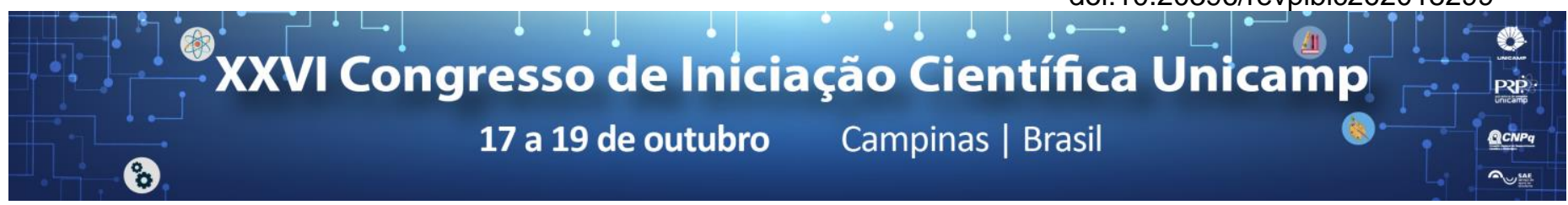

\title{
Análise de sensibilidade aplicada ao planejamento de produção do setor sucroalcooleiro
}

\section{Caroline R. Silveira*, leda Geriberto Hidalgo}

\begin{abstract}
Resumo
A análise de sensibilidade de um modelo poderá identificar em que ponto este é mais sensível à mudança de valores, resultando em diferentes propostas para as variáveis. A partir dessa informação é possível avaliar quais os dados ou parâmetros sensíveis do modelo. Nesse trabalho, o objetivo da análise de sensibilidade é definir, através de um modelo matemático, quão sensível ele é em relação à variação dos preços das commodities do setor sucroalcooleiro. A formulação utilizada é conhecida como problema do mix de produção e baseia-se numa variação do problema de multiprodutos, ou seja, considera-se na abordagem adotada, a produção dos derivados a partir dos subprodutos da cana-de-açúcar com seus respectivos preços de mercado e custos de produção.
\end{abstract}

\section{Palavras-chave:}

Setor Sucroalcooleiro, Análise de Sensibilidade, Modelo de Otimização.

\section{Introdução}

Este projeto tem por objetivo principal fazer uma análise de sensibilidade em função das variações dos preços das commodities agroindustriais da cana-de-açúcar para obter uma configuração ótima do mix de produção dos seus derivados. Será utilizado um modelo de otimização desenvolvido com o objetivo de maximizar o lucro da empresa. O lucro obtido corresponde à diferença entre as receitas totais obtidas e os custos no processo de produção.

A expectativa é de que o resultado desse projeto possa subsidiar as decisões do produtor com informações relativas à alocação de recursos para a fabricação das commodities e atendimento das demandas energéticas do processo de produção na indústria sucroalcooleira. A contribuição desta pesquisa é baseada em uma análise detalhada do planejamento de produção e alocação de recursos em função das variações dos preços que influenciam a tomada de decisão.

\section{Resultados e Discussão}

Os resultados foram analisados avaliando o quão sensível a solução ótima é a mudanças nos coeficientes da equação. O modelo matemático utilizado consiste na reprodução da operação industrial horária sucroenergética cuja manufatura de bens, a partir de um mesmo recurso, se dá de forma simultânea. Essa formulação é chamada de mix de produção e baseia-se numa variação do problema de multiprodutos, explorada pela Pesquisa Operacional (MORANDIN et al., 2011)2 .

O modelo matemático foi acrescido de definição de restrições de atendimento às demandas de commodities, de atendimento à demanda energética e de recursos. Além disso, restrição de "não-negatividade" foi considerada na análise, uma vez que as usinas devem atender contratos de venda pré-estabelecidos, garantindo que a produção de cada derivado da canade-açúcar seja positiva.

Como resultado, pudemos obter dados referentes aos valores de variações dos preços das commodities que afetam significativamente a decisão do mix de produção, auxiliando no planejamento de uma usina e permitindo uma maximização das receitas em conjunto com a minimização dos custos econômicos, o que resultará na produção das commodities cujo perfil aumenta o lucro.

$$
\begin{aligned}
& \max \left(\sum_{i=1}^{5}\left(P_{i} \cdot X_{i}\right)+\left(P_{6} \cdot X_{e t a} \cdot \eta_{6}\right)-\left(\sum_{i=1}^{5} \sum_{j=1}^{4}\left(C_{i j} \cdot X_{i j}\right)+\sum_{h=1}^{3} \sum_{j=1}^{2}\left(C_{h j} \cdot X_{h j}\right)\right)\right. \\
& \text { commodities, } i=1 \ldots 6 \quad \text { (1: açúcar VHP, 2: açúcar VVHP. } \\
& \text { 3: etanol anidro; } 4 \text { etanol hidratado: } \\
& \text { 5: eletricidade excedente, } 6 \text { levedura seca): } \\
& \text { recursos, } j=1 \ldots 4 \text { (1: palha, 2: bagaço, } 3 \text { : caldo, 4: melaço) } \\
& \text { energia, } h=1 \ldots 3 \quad \text { (1: térmica, 2: mecânica, 3: elétrica); } \\
& \text { preço unitário da commodity } i \text { : } \\
& \text { quantidade horária da commodity } i \text { : } \\
& \text { custo da commodity } i \text { produzida a partir do recurso } j \text { : } \\
& \text { quantidade da commodity } i \text { produzida a partir do recurso } j \text { : } \\
& \text { preço unitário da levedura seca: } \\
& \text { quantidade horária da commodity etanol produzida: } \\
& \text { parâmetro de eficiència da relação entre a quantidade total de álcool e de levedura seca: } \\
& \text { quantidade da energia } h \text { produzida a partir do recurso } j \text { : } \\
& \text { custo da energia } h \text { produzida a partir do recurso } j \text {. }
\end{aligned}
$$

Figura 1. Modelo matemático utilizado para a análise de sensibilidade (CARVALHO, 2016) ${ }^{1}$

\section{Conclusões}

Foi possível verificar maiores lucros na etapa industrial quando os preços do etanol, em especial o anidro, foram incrementados. A explicação para isso se dá por conta da valorização desta commodity e sua representatividade energética. $O$ etanol anidro é destinado à mistura com a gasolina, enquanto o hidratado compete com o combustível fóssil, substituindo-o quando a diferença entre os preços mostra-se vantajosa.

\section{Agradecimentos}

Agradeço o incentivo e apoio do Conselho Nacional de Desenvolvimento Científico e Tecnológico (CNPq).

\footnotetext{
${ }^{1}$ CARVALHO JUNIOR, P. C. Modelo de otimização aplicado ao balanço econômico da cogeração de energia, produção de álcool e açúcar na indústria canavieira. Dissertação (Mestrado) - Universidade Estadual de Campinas, 2016.

2 MORANDIN, M.; TOFFOLO, A.; LAZZARETTO, A.; MARÉCHAL, F.; ENSINAS, A. V.; NEBRA, S. A. Synthesis and parameter optimization of a combined sugar and ethanol production process integrated with a CHP system. Energy, v. 36, n. 6, p. 3675-3680, 2011.
} 